\title{
Development of an Ecologically Friendly Method for the Chemical Treatment of Industrial Wastewater Generated in the Oil Industry
}

\author{
Hajiyeva SR, Shamilov NT*, Bayramov GI, Rakida NM and Jafarova NM \\ Baku State University, Azerbaijan
}

*Corresponding author: Shamilov NT, Baku State University, AZ 1148 Baku, Z. Khalilov st 23, Azerbaijan, Email: nshamilov@yandex.com

\section{Commentary}

Volume 4 Issue 5

Received Date: July 31, 2020

Published Date: August 13, 2020

DOI: $10.23880 /$ jenr-16000211

\section{Abstract}

Using the new ecologically effective chemical method developed by us for cleaning IWW produced in the oil industry, the amount of oil was $\sim 0 \%$, the amount of suspended particles was $\sim 0 \%$, and the color became completely transparent. For the developed new method, the IWW was cleaning temperature range is from $5^{\circ} \mathrm{C}$ to $20^{\circ} \mathrm{C}$. To purify oil from the composition of ITS samples taken from oil producing enterprises (excluding the Balakhany oil producing enterprise) using the developed purification method, we mainly used the K-1 coagulant solution, a mixture of K-2 extragenic oil-hydrocarbon solvent and K-3 flotoculant. A special optimal mode was developed for the use of reagents, conventionally designated K-1, K-2 and K-3 alongside with this, comparative scientific studies with several reagents were repeatedly conducted. Coagulant K- 1 subsequently passes into purified water. The K-2 component remaining in the organic layer - as part of the oil layer, since it consists of a mixture of oil and hydrocarbons, does not adversely affect the quality of the oil.

Keywords: Oil; Ecological; Inhibitor; Industrial Wastewater; Coagulant; Flotoculant; Extragent

\section{Introduction}

The oil industry operates mainly in the direction of the oil production and oil refining industries. So, the oil industry includes oil production from various depths, accumulation and primary purification from gas, water, mechanical impurities, at the last stage, preparation as a commodity raw material and operations for transportation and sale. Desalination of oil is carried out in the oil refining industry, dehydration, atmospheric vacuum distillation, preparation of distillates (fractions) as commodity products, storage operations, delivery and sales.

In the process of oil production and processing, industrial wastewaters are obtained which vary greatly in composition. Our studies have shown that in oil production, in industrial wastewater generated during the preparation of oil as a commodity raw material, a medium containing various oil emulsions (with hydrophobic and hydrophilic properties), mainly sulfates, chlorides, addictive items is mainly neutral $(\mathrm{pH} \sim 6.85-7.25)$. The generated wastewater is mainly related to oil extracted from Neft Dashları, Oil and gas extraction named after A.Amirov oil fields. The wastewater obtained during the refining of heavy and light Balakhany oil is very different from that contained in other oils. That is why oil extracted from different fields and differing from each other mainly in composition, in the process of preparation as a marketable raw material, industrial waste waters differing from each other is obtained.

Research is being carried out in several directions to develop new methods for the ecologically efficient treatment of samples taken from wastewater formed as a result of treatment, as well as the processing of various oils in Azerbaijan. The presence of impurities in the liquid and gas state, as well as oil emulsions in wastewater obtained during extraction and processing in the oil industry, contributes to environmental pollution of the atmosphere, lithosphere and, 


\section{Journal of Ecology and Natural Resources}

mainly, the hydrosphere in all existing cleaning processes.

Therefore, for many years, conducting the research in the field of deeper ecologically efficient treatment of industrial waste generated at both enterprises of the oil industry has been considered as the main current issues of our time. Thus, completely deeply untreated industrial wastes, the indicators of which exceed the required sanitary standards, which are higher than environmental standards, cause long-term ecological problems in the biosphere from these industries. Due to the low requirements for the speed of treatment of industrial wastewater (IWW) generated in the oil industry, we have developed a new chemical method for deep treatment of these IWWs in the preparation of oil as a commercial product using the most cost-effective and ecologically effective special reagents.

Using the developed new chemical method, a deep environmentally effective purification of oil from water in reservoirs where crude oil is stored, as well as a deep purification of IWW containing an oil emulsion have been achieved. As shown by the results of previous and ongoing studies on the purification of IWW, generated in the oil industry [1], until now no chemical treatment has been carried out that does not affect the quality of crude oil and meets ecological safety requirements. As in the countries of the world with a developed oil industry, in Azerbaijan also during primary oil production - preparation as a commodity raw material in some cases with a certain degree of heating, mainly mechanical cleaning of water is carried out by mechanical deposition in the tanks with long interruptions. At the same time, deep cleaning of the resulting IWW containing stable oil emulsions (hydrophilic, hydrophobic emulsions) is impossible. Complete deep cleaning of these waters up to $100 \%$ in several stages of mechanical, physicochemical, chemical and biological treatment has not been achieved. Therefore, amount of mechanical impurities in oils prepared as commercial raw materials should be 0.05 $\mathrm{mg} / \mathrm{l}$, and the amount of water should be $1 \%$. Using the new ecologically effective chemical method developed by us for cleaning IWW produced in the oil industry, the amount of oil was $\sim 0 \%$, the amount of suspended particles was $\sim 0 \%$, and the color became completely transparent. For the developed new method, the IWW was cleaning temperature range is from $5^{\circ} \mathrm{C}$ to $20^{\circ} \mathrm{C}$.

To purify oil from the composition of ITS samples taken from oil producing enterprises (excluding the Balakhany oil producing enterprise) using the developed purification method, we mainly used the K-1 coagulant solution, a mixture of K-2 extragenic oil-hydrocarbon solvent and K-3 flotoculant. A special optimal mode was developed for the use of reagents, conventionally designated $\mathrm{K}-1, \mathrm{~K}-2$ and $\mathrm{K}-3$ alongside with this, comparative scientific studies with several reagents were repeatedly conducted. The following ecologically and economically significant results were obtained:

Coagulant $\mathrm{K}-1$ subsequently passes into purified water. The K-2 component remaining in the organic layer - as part of the oil layer, since it consists of a mixture of oil and hydrocarbons, does not adversely affect the quality of the oil. Experimental work was also carried out on the use of a new ecologically effective chemical method developed by us for the use of a mixture consisting of oil and $\mathrm{K}-2$ extragent solvent obtained by refining IWW formed in oil production, for in certain amount in IWW refining. Experiments were conducted and very good results were obtained on the reuse of a mixture of oil obtained during the cleaning of IWW in the oil and refining industry and $\mathrm{K}-2$ in tanks for cleaning from water and mechanical mixture (during mechanical cleaning by sedimentation). Thus, ensuring the use of the primary component of $\mathrm{K}-2$ in the refining process together with longterm refined oil can be considered economically feasible. Based on the results of our studies on the ecologically efficient cleaning of IWW generated in the oil industry, the application of the new method developed by us in the industry can be considered scientifically sound. Thus, it is possible to guarantee the use of the aforementioned method for carrying out deep ecologically and cost-effective water purification during the oil preparation process as a commodity raw material (i.e. purification from water, mechanical impurities) in oil producing enterprises of Azerbaijan (excluding Balakhany oil producing enterprise) and refining from water IWW obtained during this process and containing an oil emulsion. Based on our research, the optimal technological mode of the developed new method was determined. The results of the study and the main parameters of the optimal technological regime are shown in Table 1. Research is also continuing on a more deeply environmentally effective chemical purification of IWW samples taken from the Balakhany oil producer and from the tank where the Balakhany heavy oil is stored for processing (from the tank of oil depot in the Boyuk Shor where the oil from the Oil Refinery Plant named after Heydar Aliyev is stored). Alongside with this, the results of our research on the purification of IWW formed in the oil refining industry, which have a very complex structure and properties compared to IWW formed in the oil refining industry showed higher rates.

A comparative analysis of the chemical composition of IWW samples formed in the oil industry using a new ecologically effective method with known methods of chemical analysis is carried out. Along with this, using special instruments, the amount of organic compounds (petroleum hydrocarbons) present in purified water and highly soluble in water was determined with known methods of analysis and their spectra have been registered. 


\section{Journal of Ecology and Natural Resources}

\begin{tabular}{|c|c|c|c|c|c|c|c|c|}
\hline \multicolumn{9}{|c|}{ IWW Samples } \\
\hline \multirow{2}{*}{ 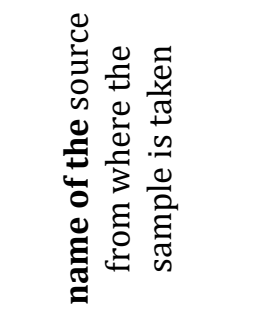 } & \multicolumn{3}{|c|}{ composition before cleaning } & \multicolumn{2}{|c|}{$\begin{array}{l}\text { used for } \\
\text { cleaning }\end{array}$} & \multicolumn{3}{|c|}{ composition after cleaning } \\
\hline & $\begin{array}{l}\text { the amount of oil, } \\
\mathrm{mg} / \mathrm{l}\end{array}$ & $\begin{array}{c}\text { amount of } \\
\text { suspended } \\
\text { particles, } \\
\mathrm{mg} / \mathrm{l}\end{array}$ & $\begin{array}{l}\grave{0} \\
\text { o } \\
\text { İ } \\
\text { a. }\end{array}$ & 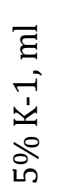 & $\begin{array}{l}\bar{\Xi} \\
\dot{m} \\
\dot{y}\end{array}$ & $\begin{array}{l}\overline{\overline{00}} \\
\Xi \\
\overline{\overline{0}}\end{array}$ & $\begin{array}{c}\text { amount of } \\
\text { suspended } \\
\text { particles, } \\
\mathrm{mg} / \mathrm{l}\end{array}$ & 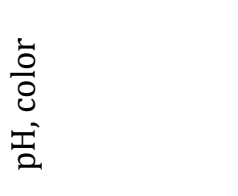 \\
\hline Neft Dashları & 500 & 150 & $\begin{array}{l}\text { Dark } \\
\text { brown }\end{array}$ & 5.0 & 1.52 & $\sim 0$ & $\sim 0$ & pH 6.75- 7.15 \\
\hline $\begin{array}{l}\text { Oil and gas } \\
\text { extraction named } \\
\text { after A.Amirov }\end{array}$ & 350 & 110 & $\begin{array}{l}\text { Blurry } \\
\text { brown }\end{array}$ & 3.5 & 1.25 & $\sim 0$ & $\sim 0$ & pH 6.85- 7.25 \\
\hline
\end{tabular}

Table 1: The results of the developed methodology for the study of deep ecologically effective chemical cleaning of IWW samples formed in the oil industry and containing oil.

We have conducted an analysis of research conducted over the past ten years on the treatment of industrial wastewater (IWW) generated in the oil and refining industries. Based on the results of the analysis it was found, that according to the research results, mechanical, adsorption, and absorption physico-chemical, chemical, thermal, biological and other processing methods are used in the oil and refining industries to clean and neutralize oil, mixture of oil production wastes (MOPW) and other harmful substances in the composition of IWW, generated in the oil and refining industries. As mentioned elsewhere [1-4], each of the methods developed and used in the oil industry for cleaning IWW has many shortages. So, the cleaning methods of IWW, generated in the oil industry are evaluated depending on their composition, degree of emulsion, degree of environmental efficiency of cleaning, class of ecological safety of the reagents used, impact on the quality of oil(MOPW) and finally ecological impact on the biosphere, economic and ecological importance. From this point of view, the new method that we have developed has justified the implementation of an important economic and ecological point of view for cleaning IWW, formed in the oil industry which contains oil emulsions.

Depending on the composition and properties of IWW, which are formed during the preparation of crude, mainly Balakhany oil as a commodity, the cleaning by the same method does not have the same efficiency. That is why it is necessary to continue long-term research to determine the selected components and the optimal regime.

\section{References}

1. Bayakhmetova ZK, Nurgalieva GO, Dzhusipbekov (2011) Purification of oily wastewater by humate-containing composite materials//Collection of materials of the AllRussian youth conference "Innovations in chemistry: achievements and prospects, Kazan, KSTU, pp: 6.

2. Sapina VN, Temnikova Ye V (2011) Patent 2415815 Russia. IPC CO2F3 / 02. The method of wastewater treatment. Publ Bull Number 10.

3. Shapkin NP (2012) Patent 2440931 Russia. IPC CO2F1 / 465. The method of wastewater treatment, Publ Bull No 3.

4. Burenin VV (2015) Protection of water bodies from pollution by oil-containing wastewater. Jour Production Ecology 2: 54-61. 